\title{
Posttraumatic Stress in Women after the September 11 Terrorist Attacks in New York City
}

\author{
TIFFANY PULCINO, B.S., ${ }^{1,2}$ SANDRO GALEA, M.D., Dr.P.H., ${ }^{2}$ \\ JENNIFER AHERN, M.P.H., ${ }^{2}$ HEIDI RESNICK, Ph.D., ${ }^{3}$ MARY FOLEY, Ed.D., 1 \\ and DAVID VLAHOV, Ph.D. ${ }^{2}$
}

\begin{abstract}
Background: Women have been shown to be at higher risk than men of developing posttraumatic stress disorder (PTSD) after traumatic events. Women in New York City were more likely than men to have probable PTSD 5-8 weeks after the September 11, 2001, terrorist attacks on the World Trade Center. We explored the factors that could explain the higher prevalence of probable PTSD among women in the aftermath of the attacks.

Methods: Data from a telephone survey of a randomly selected group of residents of Manhattan living south of 110th street, conducted 5-8 weeks after September 11, were used in these analyses. The survey assessed demographic information, lifetime experience of traumatic events, life stressors, social support, event exposure variables, perievent panic attacks, postevent concerns, and probable PTSD related to the attacks. We determined the contribution of key covariates that could explain the gender-probable PTSD relation through stratified analyses and manual stepwise logistic regression model building.

Results: Among 988 respondents, women were two times more likely than men to report symptoms consistent with probable PTSD after the September 11 attacks. When adjusted for potential confounders, the association between gender and probable PTSD diminished from $\mathrm{OR}=2.2(95 \%$ confidence interval $[C I] 1.3-3.6)$ to $\mathrm{OR}=1.2(95 \% \mathrm{CI} 0.7-2.2)$.

Conclusions: These results suggest that specific behavioral and biographic factors (including previous traumatic experiences and psychological disorders, social responsibilities, and perievent emotional reactions) explained most of the excess burden of probable PTSD among women after a disaster. Isolating the characteristics that place women at greater risk for probable PTSD after disasters can inform public health prevention strategies and spur further research.
\end{abstract}

\section{INTRODUCTION}

$\mathbf{W}$ OMEN HAVE BEEN SHOWN to be at greater risk than men of developing posttraumatic stress disorder (PTSD) after traumatic events. ${ }^{1-8}$ This increased risk has been documented in adolescence and adulthood, both among women who are survivors of individual traumatic events (e.g.,

\footnotetext{
${ }^{1}$ Mount Sinai School of Medicine, New York, New York.

${ }^{2}$ Center for Urban Epidemiologic Studies, New York Academy of Medicine, New York, New York.

${ }^{3}$ National Crime Victims' Research and Treatment Center, Medical University of South Carolina, Charleston, South Carolina.

This work was supported by grants from the United Way of New York City and The New York Community Trust, The Commonwealth Fund, the MetLife Foundation, the National Institute on Drug Abuse of the National Institutes of Health (K01 DA14219-0151), and the National Institute of Mental Health (R01 MH66081-01).
} 
rape, assault) and among woman who are survivors of mass disasters. ${ }^{1}$ The disparity in prevalence of PTSD between women and men was also documented in a study of residents of Manhattan conducted 5-8 weeks after the September 11, 2001, attacks on the World Trade Center. This study found that whereas the overall prevalence of probable PTSD related to the September 11 attacks was $7.5 \%, 9.9 \%$ of women and only $4.8 \%$ of men met criteria for probable PTSD. ${ }^{7}$ Two other studies examining the symptoms of PTSD after September 11 also showed that female gender was associated with an increased risk of PTSD. ${ }^{4,6}$

Several hypotheses have been suggested to explain this gender difference in PTSD prevalence. First, it has been hypothesized that women experience traumatic events differently from men. Although men experience more traumatic events than women, the overall incidence of PTSD in men is lower than it is in women. ${ }^{9-12}$ However, women's conditional risk for PTSD associated with both mass disasters and other traumatic experiences, such as mugging, has been shown to be greater than among men in several studies. $^{3-8,11-19}$ This elevated risk may be due to qualitative gender-related differences in the way an event is experienced. ${ }^{1,10-16}$

Second, women may have more ancillary stressors associated with traumatic events than men. It is well established that persons who experience heavier personal and financial losses after traumatic events are at an increased risk of developing PTSD. 5,7,8,11,17 Women appear both to have a greater investment in, and reliance on, interpersonal relationships than men. ${ }^{18,19}$ Women are also more likely to be the primary caretakers of children or to be single parents. Thus, it is plausible that stresses about loved ones or personal losses (e.g., loss of a friend or relative) may have a greater impact on women than men after traumatic events.

Third, it has been hypothesized that traditional gender-based social and behavioral patterns may contribute to the gender disparity in PTSD prevalence. There are several forms of evidence for this hypothesis. The disparity in PTSD prevalence between genders is greater in developing nations, where women hold more traditional gender roles in society (e.g., as primary caretakers of children), than in the United States when similar traumatic events are compared. ${ }^{20}$ In addition, women traditionally maintain more emotionally intimate relationships and mobilize more social supports during periods of stress than men. This network mobilization can increase women's exposure to, and responsibility for, problems within their community. ${ }^{21}$ Further, it has been shown that among police officers, who are socialized into an environment of similar gender roles, there is no significant gender difference in prevalence of PTSD after traumatic event experiences. ${ }^{22,23}$

Fourth, previous psychological disorders, such as PTSD or depression, are associated with an increased probability of developing PTSD after a new traumatic experience. ${ }^{5}$ The greater prevalence of baseline psychological disorders documented in national surveys among women may account for the higher prevalence of PTSD among women after individual traumatic events or mass disasters. $^{13}$

We were interested in building on previous research and assessing why women had a higher prevalence of probable PTSD after the September 11 terrorist attacks in order to identify groups to which postdisaster interventions should be targeted. In particular, we were interested in building on our work that showed that in crude analyses, women had a higher prevalence of PTSD than men after the attacks. ${ }^{7}$ We hypothesized that the higher prevalence of probable PTSD among women was due to the psychological impact of previous traumatic events, ancillary stressors related to the attacks, social and behavioral patterns placing women in situations of increased risk, and previous psychological disorders.

\section{MATERIALS AND METHODS}

\section{Data collection}

Data were collected through telephone interviews with a random sample of adults ( $>17$ years old) living in Manhattan south of 110th Street between October 16, 2001, and November 15, 2001. The survey was reviewed and approved by the Institutional Review Board of the New York Academy of Medicine.

A structured questionnaire, available in both English and Spanish, elicited information about demographic characteristics, where respondents lived before September 11, and if respondents were the primary caretakers of children in the household. Random-digit dialing was used to screen households for geographic eligibility, and an adult in each household was randomly se- 
lected to be interviewed. The overall cooperation rate of the survey was $64.3 \%$. This cooperation rate is based on the sum of the number of completed interviews, quota outs, and screen outs divided by the sum of completed interviews, quota outs, screen outs, refusals, and premature terminations.

Demographic information, such as age, gender, income, educational level, marital status, and status as the primary caretaker of children in the household, was obtained from the respondent. To assess lifetime experience of traumatic events, respondents were asked if they ever had experienced a list of traumatic events modified from the Diagnostic Interview Schedule (DIS) (e.g., forced unwanted sexual contact, natural disasters, serious accidents). ${ }^{24}$ The number of traumatic events experienced was summed and divided into categories $(0,1,2-3, \geq 4)$. Forced unwanted sexual contact was examined separately because of its potential particular importance in this context. Eight stressful events that could have occurred within the year previous to September 11 were evaluated to assess baseline levels of life stressors before the disaster. These 8 items were chosen from the Stressful Life Experiences Short Form, a 20-item screening tool that includes personal event experiences, such as disasters and accidents. ${ }^{25}$ Report of mental or emotional problems and summary measures of the total number of stressful events reported were coded for analysis. In addition, we assessed social support available to the respondent in the 6 months prior to September 11 using a modified version of a social support measure from the Medical Outcomes Study focusing on emotional, instrumental, and appraisal support. ${ }^{26}$ Levels of social support were summarized and divided into thirds of low, medium, and high for analysis.

Individual experiences related to both the September 11 attacks and its consequences were assessed using questions pertaining to the location of the respondent during the attack, whether injuries were sustained, the loss of property, death or injury of relatives, friends, and acquaintances, their involvement in the volunteer effort, and job status. Level of concern regarding issues related to the attacks (e.g., America's War on Terrorism, the possibility of future terrorist attacks, harm from exposure to dust or chemicals from the World Trade Center) was also assessed. Concern was measured for each factor on a 5-point Likert scale (1, least concerned-5, most concerned). A summary measure of concern was created for analysis by summing these levels of concern and dividing the summed measures into categories. Perievent panic attack was measured using a modified version of the DIS measure for panic attack. ${ }^{24}$ The presence of four or more symptoms occurring in the "first few hours after" the events of September 11 contributed to a diagnosis of a perievent panic attack.

PTSD was assessed using the PTSD module from the National Women's Study, a tool developed for the assessment of large samples of adult women surveyed about topics, including history of traumatic events and PTSD, that has been used in a number of random-digit dialing studies. ${ }^{27,28}$ This module was validated in a field trial against the Structured Clinical Interview for DSM-III-R (SCID) and was found to be comparable for identification of current PTSD (kappa 0.71). Instrument sensitivity was $99 \%$, and specificity was $79 \%$ compared with SCID diagnosis. ${ }^{29,30}$ Probable PTSD was defined as the presence of at least one of criterion $\mathrm{B}$ or reexperiencing symptoms (e.g., intrusive memories or distressing dreams), three of criterion $\mathrm{C}$ or avoidance symptoms (e.g., efforts to avoid thoughts associated with the trauma), and two of criterion D or symptoms of hyperarousal (e.g., difficulty falling asleep or concentrating). Content-specific symptoms (e.g., nightmares) had to be specifically related to the September 11 terrorist attacks to contribute to probable PTSD. To qualify as symptoms of current probable PTSD, all symptoms must have persisted for more than 2 weeks and must have been present within the previous 30 days.

\section{Statistical analysis}

All analyses were weighted to account for potential bias due to the number of telephones and adults in each household. We present covariates stratified by gender to show differences in covariate association with prevalence of PTSD within strata of gender. We used two-tailed chisquare tests to identify significant associations $(p<0.05)$ among covariates of interest, gender, and probable PTSD in unstratified analyses. Variables significantly associated $(p<0.05)$ with both probable PTSD and gender in bivariate unstratified analyses were considered as potential explanatory variables. These variables were considered for inclusion in multivariable logistic regression models of the relationship between 
gender and probable PTSD related to the attacks. The final multivariable regression model was built using manual stepwise model building, where one variable was added at a time to determine the sequential effect of subsequent variable addition on the relation between gender and probable PTSD. Those variables that when included in the model accounted for some part of the increased risk of probable PTSD associated with gender $(\geq 10 \%$ change in gender regression parameter) were retained in subsequent models.

\section{RESULTS}

Overall, 988 persons were included in this analysis. Fifty-two percent of respondents were women, and the mean age was 42 years, with a standard deviation (SD) of 15 years. Other demographic factors and residence distributions in our sample were consistent with estimates from the 2000 U.S. Census for this sampling frame, as noted in previously published studies. For example, $52.0 \%$ of respondents in our study were women (comparable to $52.8 \%$ women in the comparable Manhattan sampling frame), 9.5\% were aged $18-24,31.2 \%$ were aged $25-34,20.0 \%$ were aged $35-44,18.0 \%$ were aged $45-54,12.2 \%$ were aged 55-64, and $9.1 \%$ were aged $\geq 65$ (comparable to $10.4 \%, 27.3 \%, 19.9 \%, 16.3 \%, 11.3 \%$, and $14.8 \%$ for each of the age categories respectively as assessed by the U.S. Census). 8,31

Table 1 shows the prevalence of probable PTSD, stratified by gender, among respondents with the specified characteristics. In stratified analysis, the covariates that were significantly associated with probable PTSD among women were age $(p=0.05)$, annual household income $(p=0.03)$, primary caretaker status $(p=0.0003)$, experience of lifetime forced unwanted sexual contact $(p=0.03)$, mental/ emotional problems in the 12 months prior to September $11(p<0.0001)$, levels of social support within the last 6 months $(p=0.02)$, perievent panic attack $(p<.0001)$, lost possessions $(p=0.0003)$, lost job because of World Trade Center disaster $(p=0.03)$, volunteered time at rescue centers $(p=0.02)$, and measures of concern $(p=0.05)$. Among men, those variables that were significantly associated with probable PTSD were marital status $(p=0.01)$, experience of forced unwanted sexual contact $(p=$ $0.02)$, mental/emotional problems in the 12 months prior to September $11(p<0.0001)$, lost possessions $(p<.0001)$, lost job because of the World Trade Center disaster $(p<0.0001)$, directly witnessing the attacks $(p=0.006)$, perievent panic attack $(p<0.0001)$, volunteered time at rescue centers $(p<0.0001)$, and measures of postevent concern $(p=0.02)$.

Covariates that were significantly associated with both gender and PTSD in unstratified analysis were primary caretaker of children in the home (female, $p=0.002$; PTSD, $p=0.0004$ ), health insurance coverage (female, $p=0.02$; PTSD, $p=0.04)$, experienced unwanted sexual contact (female, $p<0.0001$; PTSD, $p=0.0004$ ), mental/emotional problems in the 12 months prior to September 11 (female, $p=0.02$; PTSD, $p<0.0001$ ), directly witnessing the event (female, $p=0.006$; PTSD, $p=0.006)$, perievent panic attack (female, $p<.0001$; PTSD, $p<0.0001$ ), concerned relative may be injured or killed (female, $p=0.04$; PTSD, $p=0.009)$, volunteering time at rescue centers (female, $p=0.03$; PTSD, $p<$ 0.0001 ), and measures of postevent concern (female $p=0.009$; PTSD, $p<0.0001$ ). Women were more likely than men to have probable PTSD, annual incomes $<\$ 20,000$, be the primary caretaker of children, experience unwanted sexual contact, experience more stressors in last 12 months, experience mental/emotional problems in last 12 months, have a perievent panic attack, be concerned about injury or death of a relative, experience death of friend, relative, or acquaintance, volunteer at rescue centers, and express high levels of concern.

Table 2 shows stepwise logistic multivariable regression model building accounting for the effect of gender on probable PTSD, with the incremental addition of covariates that improved model fit. Both experiences of unwanted sexual contact $(p=0.6)$ and categories of concern $(p=$ 0.1 ) were not statistically significant in the final multivariable regression model. However, both partly accounted for the increased prevalence of PTSD among women. In the final model, covariates significantly associated with probable PTSD were primary caretaker status of children in the household (odds ratio [OR] $=2.5$ ), mental/emotional problems in the 12 months prior to September $11(\mathrm{OR}=2.3)$, perievent panic attacks $(\mathrm{OR}=7.0)$, and volunteered time at rescue centers $(\mathrm{OR}=2.9)$. When adjusted for potential confounders, the association between gender and probable PTSD diminished from $\mathrm{OR}=2.2$ 


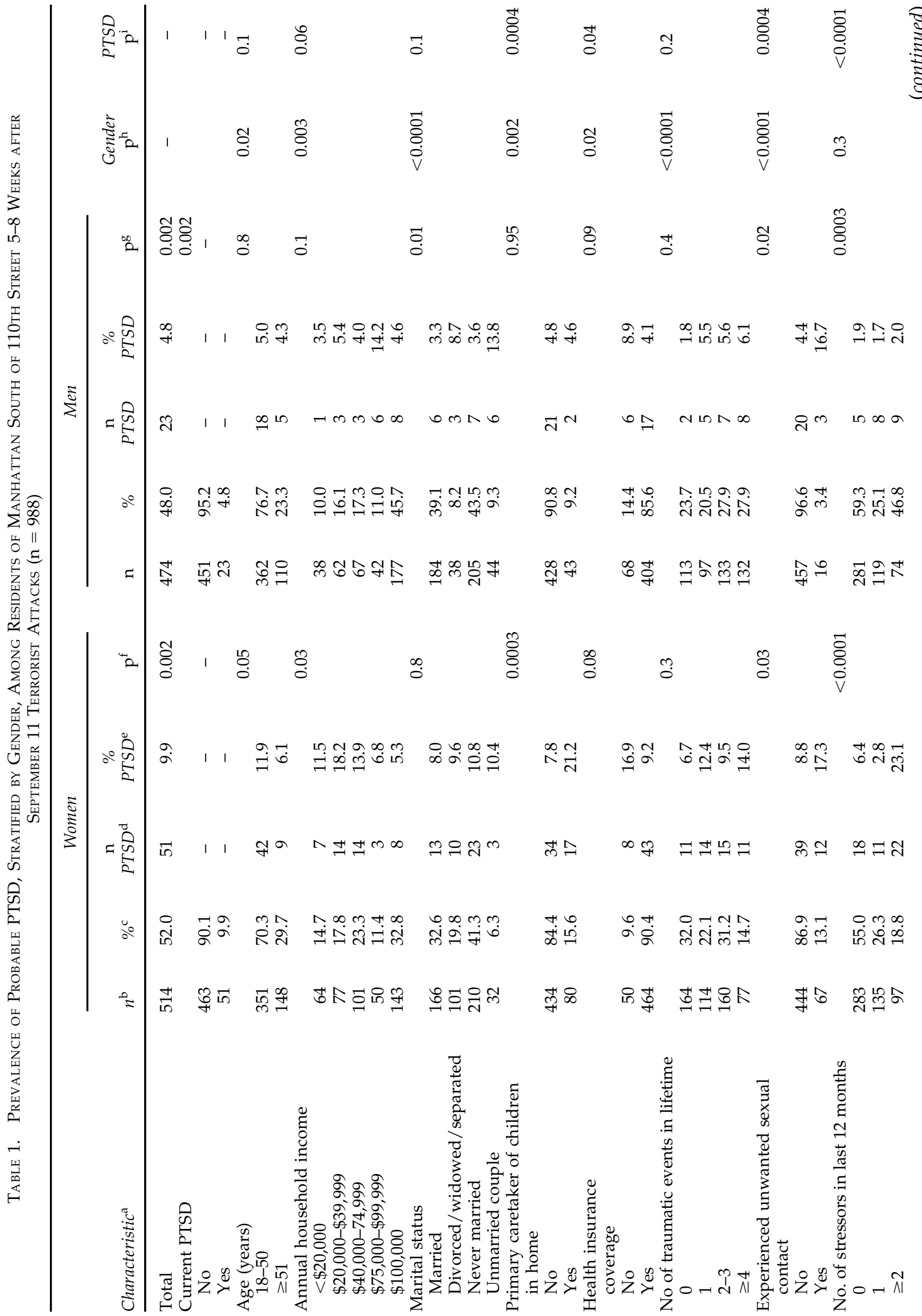




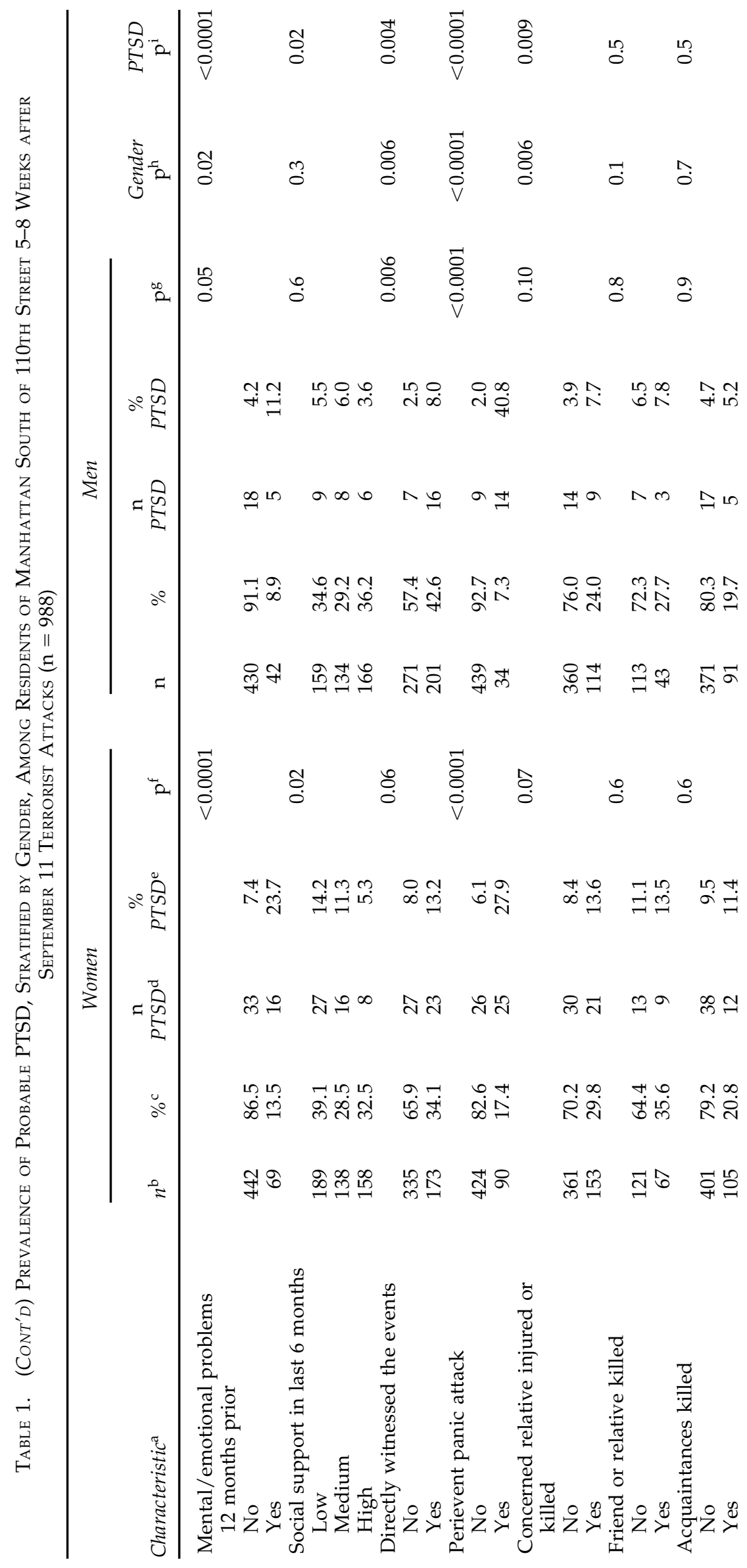




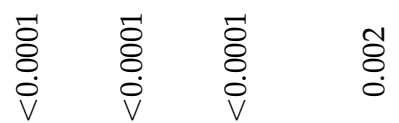

$$
\begin{aligned}
& \text { 명 : }
\end{aligned}
$$

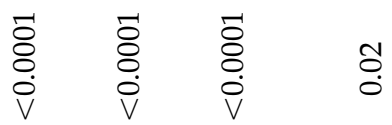

$$
\begin{aligned}
& \text { 舟年 } \\
& \text { AT Ma on } \rightarrow A+4
\end{aligned}
$$

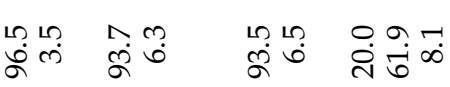

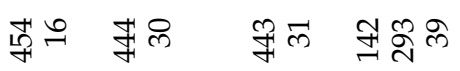

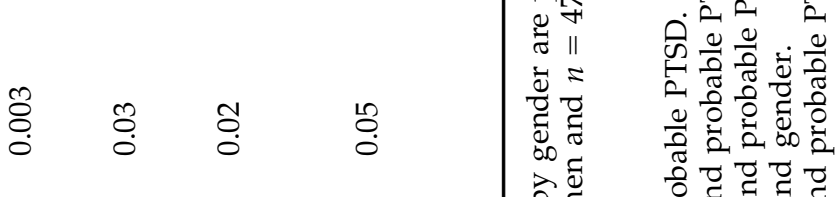

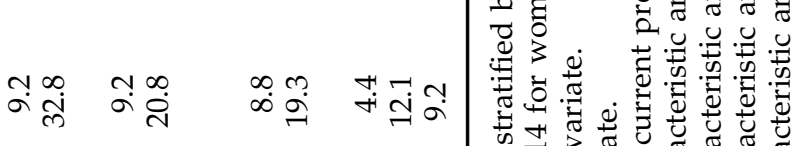

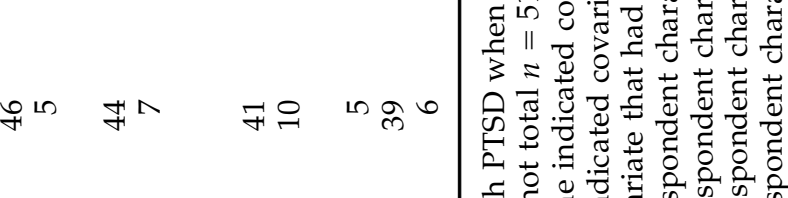

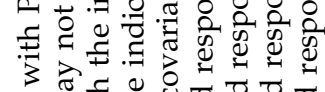

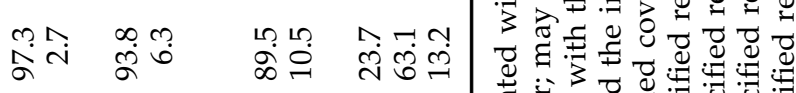

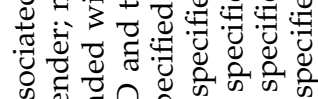

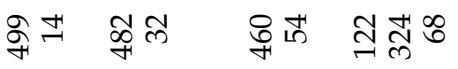

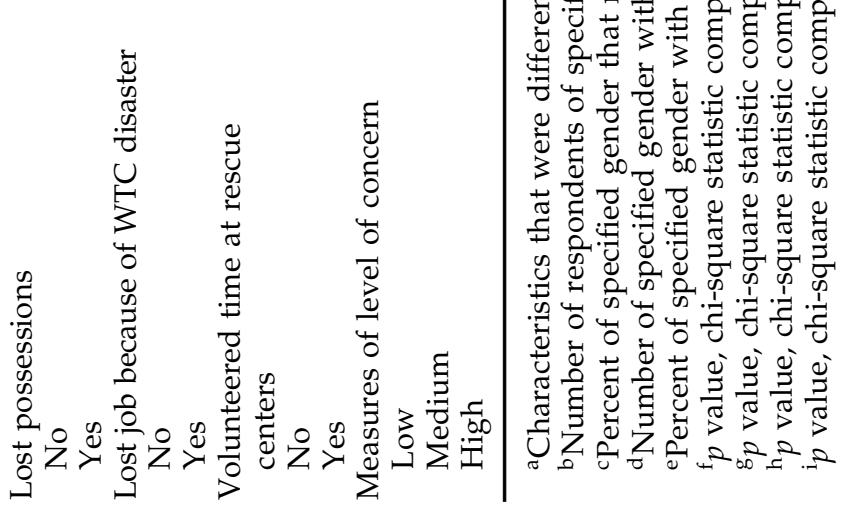




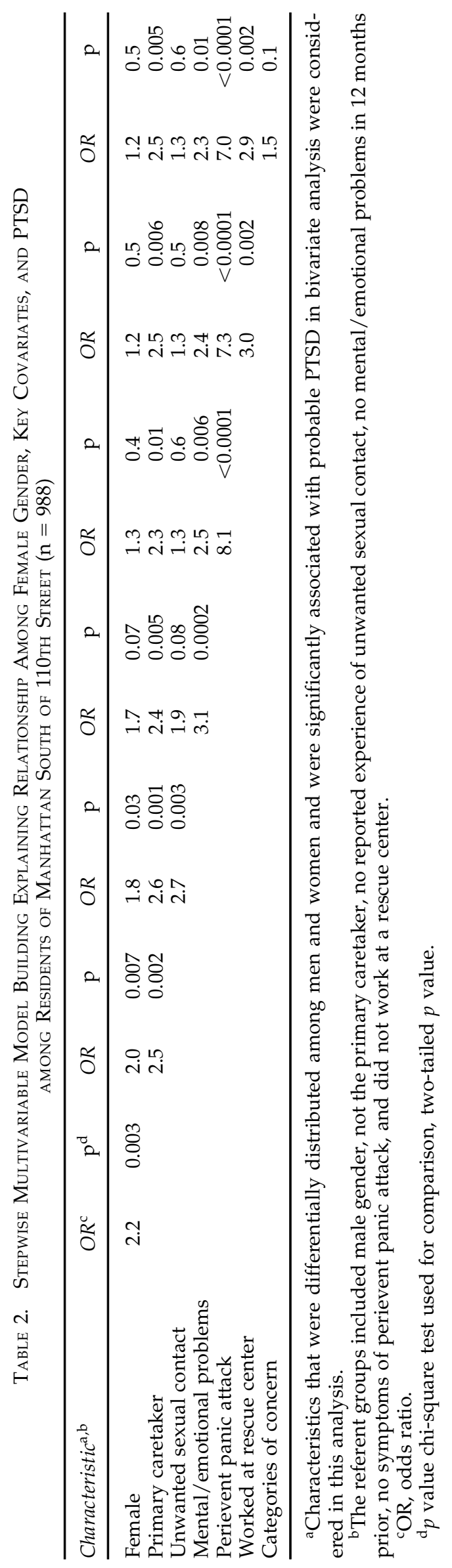


(1.3-3.6) in the bivariate gender-probable PTSD model to $\mathrm{OR}=1.2(0.7-2.2)$.

\section{DISCUSSION}

One to two months after the September 11 attacks, women were twice as likely as men to report symptoms consistent with probable PTSD related to the attacks. Factors that explained this higher prevalence of probable PTSD in multivariable analyses were previous unwanted sexual contact, status as primary caretaker of children, having worked at rescue centers, concern for the community at large, having had mental or emotional problems in the 12 months prior to the attacks, and having experienced a panic attack during or soon after the attacks.

The observation that probable PTSD was higher among women than among men after the September 11 attacks is consistent with results from other studies of PTSD after traumatic experiences. $3,10,12,14,16,17,32$ In this analysis, we examined the role of four factors that could explain the higher prevalence of probable PTSD documented among women after the September 11 terrorist attacks. We hypothesized that the traumatic events experienced by women before a disaster in part explained this disparity. We found that although women were less likely than men to experience any kind of traumatic event prior to the September 11 attacks, women were four times more likely than men to report experiencing unwanted sexual contact. The experience of unwanted sexual contact was associated with probable PTSD among women and men. Controlling for other significant variables, previous unwanted sexual contact increased the risk of a woman having symptoms consistent with probable PTSD related to the September 11 attacks by 33\%. The impact of previous traumas on postdisaster PTSD is controversial. Women and men may experience different amounts of trauma with different intensity, or there may be gender-specific attributes of traumatic events that account for the relation between disasters and PTSD. Our results are consistent with several studies that have shown that women are less likely than men to report traumatic experiences and that traumatic experiences overall are more likely to be associated with PTSD among women than men. ${ }^{9-10,12,14,16}$ This was true in the current study in terms of exposure to various aspects of the events that occurred on September 11 (e.g., directly witnessing the event was more frequent among men). However, across the lifespan, women have also been shown to experience higher rates of some types of events that are associated with increased risk of PTSD for both men and women, relative to other types of events. For example, it has been shown that women experience higher rates of rape and other sexual assault than men ${ }^{12,33}$ and that these experiences are more likely to lead to PTSD than are other traumatic experiences. ${ }^{10,12,14,15}$ Our findings suggest that previous sexual assault experienced by women may have played a role in the elevated prevalence of probable PTSD after September 11 and that women who are survivors of rape and sexual assault may benefit from targeted counseling and support after mass disasters.

High levels of stress may decrease one's ability to cope with traumatic events. We hypothesized that the presence of more ancillary stressors (e.g., higher levels of preevent stress, financial and personal losses) associated with the September 11 attacks may have increased the risk for the subsequent development of probable PTSD among women. In this analysis, we found no significant difference between men and women in baseline stress levels or financial or personal losses. The presence of these stressors in both men and women in this study was associated with a greater likelihood of developing PTSD. Our findings are consistent with previous studies that have shown that past year stressful events and financial losses increased the likelihood of current PTSD. $8,17,27$ However, unlike previous studies, ${ }^{14}$ personal losses were not associated with a higher risk of PTSD among women than men. Ancillary stressors related to traumatic events, although significant predictors of probable PTSD, did not account for the gender difference in prevalence of PTSD in the wake of the September 11 attacks. The overwhelming loss associated with the September 11 attacks and the extent to which all New Yorkers were directly or indirectly affected by the attacks may explain why we did not observe a gender difference in the role of ancillary stressors and probable PTSD in this analysis.

We hypothesized that women in more traditional gender-based social and behavioral roles would be more vulnerable to PTSD in the wake of the September 11 attacks. Traditional gender roles were operationalized as lower income, indicating poor financial control, status as the 
household's primary caretaker, low degree of social support, and concern for the community. We found that although there was a significant gender difference in income, with a preponderance of women in the lower income strata, income was not a significant predictor of probable PTSD. Primary caretaker status was a significant predictor of probable PTSD, indicating that women who act as primary caretakers experience more stress related to mass disasters, perhaps because of their perceived burden of protecting and caring for their children. This effect of caretaker status, a social role, could account for the wider difference in incidence of PTSD between genders in more traditional societies and the lack of significant gender differences in PTSD among those in nontraditional gender roles, such as police officers. ${ }^{22,23}$ We also found that there was a lower prevalence of probable PTSD among women with high levels of social support in the 6 months prior to the September 11 attacks. Among women, the prevalence of probable PTSD increased as the degree of social support decreased, whereas social support was not a significant predictor of probable PTSD among men. Volunteering at rescue centers was associated with probable PTSD among women. This result is consistent with studies that document that women maintain more emotionally close relationships and tend to mobilize more social supports during periods of stress than men. ${ }^{21}$ These relationships, when demanding, as in periods of stress, have a greater negative impact on women than on men. ${ }^{19,34}$ The effect of acting as the primary caretaker of children in the home must be carefully separated from the effect of other demanding social ties, given the unique effects of the caretaker-child relationship. ${ }^{35}$ Women with low levels of social support, including elderly and homebound women, benefit from targeted interventions that mobilize social support from families, friends, and community organizations to prevent and treat psychological distress after disasters. ${ }^{1}$

We hypothesized that previous psychological disorders would be associated with an increased risk of developing probable PTSD related to the September 11 attacks. In our data, more women reported prior mental/emotional problems, and these problems were associated with having twice the likelihood of having symptoms consistent with probable PTSD after the September 11 terrorist attacks. In adjusted models, reports of mental/emotional problems in the previous 12 months increased the likelihood of developing probable PTSD after the attacks. Previous studies have shown that women experience higher prevalence of both current and lifetime affective and anxiety disorders. Kessler et al. ${ }^{13}$ showed that among women, the prevalence of major depressive disorder in the previous 12 months was $12.9 \%$, whereas among men, it was $7.7 \%$. Preexisting major depression in women increases their risk for developing PTSD after exposure to a traumatic event more than 2 -fold, ${ }^{12,33,36}$ although, it is unclear if preexisting depression has a different effect on women than men. We also found that women were more likely to experience perievent panic attacks and that this explained $33 \%$ of the relation between gender and probable PTSD in this dataset. Research has highlighted the role of perievent emotional reactions in the subsequent development of PTSD. ${ }^{7,28,37}$ Whereas women with a documented history of prior psychological problems may benefit from targeted screening after disasters, the identification of perievent symptomatology that is predictive of subsequent PTSD development may suggest avenues for rapid postdisaster interventions that can decrease the eventual burden of PTSD among women.

It is important to note several limitations to this study. First, there are a number of other factors that we did not measure in this survey that could account for some of the unexplained gender disparity in probable PTSD prevalence. Women are more willing to seek mental health treatment and also could be more willing than men to report symptoms of PTSD. Our survey did not include a detailed past psychological history, limiting the conclusions we can draw from respondents' reports of previous mental or emotional problems. Second, it is possible that our sample introduced bias that was not accounted for by our analytical strategy. This is unlikely, given the representativeness of the sample and the fact that this analysis focuses primarily on explanation of an observed association rather than on determination of absolute prevalence. Third, we note that some of the conclusions drawn in this paper are limited by the modeling technique used. In order to best understand the range of variables that may be important to explain the gender-PTSD relation, we included all variables that may statistically explain this relation (i.e., variables that were associated with both gender and with probable PTSD in bivariate analyses). However, some of 
these variables may have a high likelihood of cooccurring (e.g., history of unwanted sexual contact and prior stressors) and, thus, are not statistically related to PTSD in the final model. We note that all the variables included in the final model are important and contribute to the relation between gender and probable PTSD. Fourth, generalization from this study to the general population must be made with caution. The New York City population is in many ways different from the general U.S. population (e.g., approximately $28 \%$ of residents of New York are foreign born, compared with $11.1 \%$ in the rest of the United States), ${ }^{31}$ and it is plausible that other variables, not discussed in this paper, partly account for the relation between gender and PTSD observed in other urban contexts.

\section{CONCLUSIONS}

One to two months after the September 11 terrorist attacks, we found that the higher prevalence of probable PTSD among women was largely explained by the effect of previous experience of unwanted sexual contact, the burden of acting as the primary caretaker for children in a household, concern for the community at large, a recent history of mental/emotional problems, and experience of a perievent panic attack. PTSD is three to four times more likely to become a chronic and debilitating disease in women than in men. ${ }^{1}$ Isolating the characteristics that increase the likelihood that women will develop PTSD may allow early identification and treatment of those at risk, reducing both the emotional and economic burden of PTSD after disasters. ${ }^{1,38}$

\section{ACKNOWLEDGMENTS}

We would like to acknowledge the interviewers at Schulman, Ronca, \& Bucuvalas Inc. for their assistance.

\section{REFERENCES}

1. Kimerling R, Ouimette P, Wolfe J, eds. Gender and PTSD. New York: The Guilford Press, 2002.

2. North C, Tivis L, McMillen J, et al. Psychiatric disorders in rescue workers after the Oklahoma City bombing. Am J Psychiatry 2002;159: 857.
3. Chen C, Yeh T, Yang Y, et al. Psychiatric morbidity and post-traumatic symptoms among survivors in the early stage following the 1999 earthquake in Taiwan. Psychiatry Res 2001;105:13.

4. Silver R, Holman E, McIntosh D, Poulin M, Gil-Rivas V. Nationwide longitudinal study of psychological responses to September 11. JAMA 2002;288:1235.

5. North C, Nixon S, Shariat S, et al. Psychiatric disorders among survivors of the Oklahoma City bombing. JAMA 1999;282:755.

6. Schlenger W, Caddell JEL, Jordan B, et al. Psychological reactions to terrorist attacks: Findings from the National Study of Americans' reactions to September 11. JAMA 2002;288:581.

7. Galea S, Ahern J, Resnick H, et al. Psychological sequelae of the September 11 terrorist attacks in New York City. N Engl J Med 2002;346:982.

8. Galea S, Resnick H, Ahern J, et al. Posttraumatic stress disorder in Manhattan, New York City, after the September 11th terrorist attacks. J Urban Health 2002;79: 340 .

9. Stretch R, Knudson K. Effects of premilitary and military trauma on the development of post-traumatic stress disorder symptoms in female and male active duty soldiers. Mil Med 1998;163:466.

10. Creamer M, Burgess P, McFarlane A. Post-traumatic stress disorder: Findings from the Australian National Survey of Mental Health and Well-being. Psychol Med 2001;31:1237.

11. Yehuda R. Post-traumatic stress disorder. N Engl J Med 2002;346:108.

12. Kessler R, Sonnega A, Bromet E, Hughes M, Nelson C. Posttraumatic stress disorder in the National Comorbidity Survey. Arch Gen Psychiatry 1995;52:1048.

13. Kessler R, McGonagle KA, Zhao S, et al. Lifetime and 12-month prevalence of DSM-III-R psychiatric disorders in the United States. Arch Gen Psychiatry 1994;51:8.

14. Breslau N, Chilcoat H, Kessler R, Peterson E, Lucia V. Vulnerability to assaultive violence: Further specification of the sex difference in post-traumatic stress disorder. Psychol Med 1999;29:813.

15. Hourani L. The mental health status of women in the Navy and Marine Corps: Preliminary findings from the perceptions of wellness and readiness assessment. Mil Med 1999;164:174.

16. Stein M, Walker J, Forde D. Gender differences in susceptibility to posttraumatic stress disorder. Behav Res Ther 2000;38:619.

17. Garrison C, Bryant E, Addy C, Spurrier P, Freedy J, Kilpatrick D. Posttraumatic stress disorder in adolescents after hurricane Andrew. J Am Acad Child Adolesc Psychiatry 1995;34:1193.

18. Siegler I, George L. Sex differences in coping and perceptions of life: The normal psychology of the aging male. J Geriatr Psychiatry 1982;16:197.

19. Robbins P, Tanck R. Gender differences in the attribution of causes for depressed feelings. Psychol Rep 1991;68:1209.

20. Norris F, Weisshaar D, Conrad M, Diaz E, Murphy A, Ibanez G. A qualitative analysis of posttraumatic 
stress among Mexican victims of disaster. J Trauma Stress 2001;14:741.

21. Kawachi I, Berkman L. Social ties and mental health. J Urban Health 2000;78:458.

22. Pole N, Best $S$, Weiss D, et al. Effects of gender and ethnicity on duty-related posttraumatic stress symptoms among urban police officers. J Nerv Ment Dis 2001;189:442.

23. Hodgins G, Creamer M, Bell R. Risk factors for posttraumatic reactions in police officers: A longitudinal study. J Nerv Ment Dis 2001;189:541.

24. Centers for Disease Control. Diagnostic Interview Schedule (DIS). In: Health status of Vietnam veterans. Supplement C: Medical and psychological procedure manuals and forms. Atlanta, GA: Centers for Disease Control, 1989:405.

25. Stamm BH. Contectualizing death and trauma: A preliminary attempt. In. Figley CF, ed. Death and trauma. New York: Brunner/Mazel, 1996.

26. Sherbourne CD, Stewart AL. The MOS social support survey. Soc Sci Med. 1991;32:705.

27. Hanson RF, Kilpatrick DG, Fredy JR, Saunders BE. Los Angeles Country after the 992 civil disturbances: Degree of exposure and impact on mental health. J Consult Clin Psychol 1995;63:987.

28. Resnick H, Kilpatrick D, Dansky B, Saunders B, Best S. Prevalence of civilian trauma and post-traumatic stress disorder in a representative national survey of women. J Consult Clin Psychol 1993;61:984.

29. Spitzer RL, Williams JBW, Gibbon M, First MB. The Structural Clinical Interview for DSM-III-R (SCID) I: History, rationale, and description. Arch Gen Psychiatry 1992;49:624.

30. Kilpatrick D, Resnick HS, Freedy JR, et al. The posttraumatic stress disorder field trial: Evaluation of the PTSD construct-Criteria A through E. In: Widiger T, Freances A, Pincus H, et al., eds. DSM-IV sourcebook.
Washington, DC: American Psychiatric Association Press, 1998;4:803.

31. Bureau of Census. Census summary tape, file 3A (STF3A). Washington, DC: Department of Commerce, 2000 (data file).

32. Breslau NB, Davis GCD, Andreski PA, Peterson ELP, Schultz LS. Sex differences in posttraumatic stress disorder. Arch Gen Psychiatry 1997;54:1044.

33. Breslau N, Davis G, Peterson E, Schultz L. Psychiatric sequelae of posttraumatic stress disorder in women. Arch Gen Psychiatry 1997;54:81.

34. Bullers $S$. The mediating role of perceived control in the relationship between social ties and depressive symptoms. Women Health 2000;31:97.

35. Gibbs MS. Factors in the victim that mediate between disaster and psychopathology: A review. J Trauma Stress 1989;2:489.

36. Shalev A, Freedman S, Peri T, et al. Prospective study of posttraumatic stress disorder and depression following trauma. Am J Psychiatry 1998;155:630.

37. Harvey AG, Bryant RA. The relationship between acute stress disorder and posttraumatic stress disorder: A 2-year prospective evaluation. J Consult Clin Psychol 1999;67:985.

38. Foa, EB. Trauma and women: Course, predictors, and treatment. J Clin Psychiatry 1997;58:S9.

Address reprint requests to: Sandro Galea, M.D., Dr.P.H.

Center for Urban Epidemiologic Studies, Room 556 New York Academy of Medicine 1216 Fifth Avenue New York, NY 10029-5283 E-mail: sgalea@nyam.org 